University of Nebraska - Lincoln

DigitalCommons@University of Nebraska - Lincoln

Publications, Agencies and Staff of the U.S.

Department of Commerce

U.S. Department of Commerce

2008

\title{
Legal Viability, Societal Values, and SPOIR: Response to D’Elia et
} al.

Robin Waples

NOAA, robin.waples@noaa.gov

Peter B. Adams

Southwest Fisheries Science Center, pete.adams@noaa.gov

James Bohnsack

Southwest Fisheries Science Center, Jim.Bohnsack@noaa.gov

Barbara L. Taylor

NOAA, barbara.taylor@noaa.gov

Follow this and additional works at: https://digitalcommons.unl.edu/usdeptcommercepub

Waples, Robin; Adams, Peter B.; Bohnsack, James; and Taylor, Barbara L., "Legal Viability, Societal Values, and SPOIR: Response to D'Elia et al." (2008). Publications, Agencies and Staff of the U.S. Department of Commerce. 439.

https://digitalcommons.unl.edu/usdeptcommercepub/439

This Article is brought to you for free and open access by the U.S. Department of Commerce at DigitalCommons@University of Nebraska - Lincoln. It has been accepted for inclusion in Publications, Agencies and Staff of the U.S. Department of Commerce by an authorized administrator of DigitalCommons@University of Nebraska - Lincoln. 


\title{
Legal Viability, Societal Values, and SPOIR: Response to D'Elia et al.
}

\author{
ROBIN S. WAPLES,${ }^{*}$ PETER B. ADAMS,$\dagger$ JAMES BOHNSACK, $\ddagger$ AND BARBARA L. TAYLOR $\S$ \\ *Northwest Fisheries Science Center, 2725 Montlake Boulevard East, Seattle, WA 98112, U.S.A., email robin.waples@noaa.gov \\ †Southwest Fisheries Science Center, 110 Shaffer Road, Santa Cruz, CA 95060, U.S.A. \\ $\ddagger$ Southeast Fisheries Science Center, 75 Virginia Beach Drive, Miami, FL 33149, U.S.A. \\ $\S$ Southwest Fisheries Science Center, 8604 La Jolla Shores Drive, La Jolla, CA 92037, U.S.A.
}

After many years of experiencing relatively benign neglect, the language in the U.S Endangered Species Act (ESA) that deals with risks to a species in a "significant portion of its range" (SPOIR) has attracted a great deal of recent attention from legal and biological perspectives (Defenders of Wildlife $v$. Norton 2001; Center for Biological Diversity v. U.S. Fish and Wildlife Service 2007; Vucetich et al. 2006; Nelson et al. 2007; Waples et al. $2007 a, 2007 \mathrm{~b})$. In the latest commentary on this topic, D'Elia et al. (2008) make 3 major points: (1) when evaluating such language, it is important to consider relevant legal decisions, (2) in our recent paper on SPOIR (Waples et al. 2007a), we ignored this step and consequently the framework we proposed is legally flawed, and (3) societal values should be considered along with biological criteria in evaluating the SPOIR language. On the first point, we believe we are in agreement. Regarding the second point, although it is true we did not attempt a detailed evaluation of case law on SPOIR, it is not true that we ignored the decisions of record. Rather, we considered these cases and concluded they provide little conclusive guidance about how to interpret the SPOIR language. We have discussed the SPOIR language and related court decisions with a number of government and private-sector lawyers, and we found no strong consensus on their import. As a consequence, and in response to a request from policy makers within our agency, we sought to develop a biological framework for interpreting the SPOIR language on the basis of biological principles consistent with existing case law.

We strongly disagree with the statements by D'Elia et al. (2008) about the relationship between our proposed framework and the Ninth Circuit Court of Appeals' decision regarding the case of the flat-tailed horned lizard (Defenders of Wildlife $v$. Norton 2001). In that case (p. 9660), the Court summarized the position of the Secretary of the Interior as follows:

The Secretary in her brief interprets the enigmatic phrase to mean that a species is eligible for protection under the ESA if it "faces threats in enough key portions of its range that the entire species is in danger of extinction, or will be within the foreseeable future." She therefore assumes that a species is in danger of extinction in "a significant portion of its range" only if it is in danger of extinction everywhere.

Not surprisingly, the Court concluded that this interpretation was arbitrary and capricious because it would render the phrase "or a significant portion of its range" entirely superfluous. If something can occur if either $a$ or $b$ is true, but $b=a$, then there is only a single choice and the "or" clause is robbed of any real power. Our SPOIR framework does not suffer from this flaw because it is designed to cover situations only when the entire species is not currently at risk in its entire range. Figure 2 of Waples et al. (2007a) illustrates several situations in which a listing under our SPOIR framework could occur; none of these scenarios would allow a listing if the SPOIR language were omitted from the statute. Therefore, our framework clearly gives "independent and separate meaning to the clauses that appear on either side of the word $o r$ " (a criterion proposed by D'Elia et al. 2008).

It appears from D'Elia et al. (2008) that the meaning of foreseeable future is at the heart of some of their concerns about the legal validity of our framework. Under the ESA (Sec. 3), a species can be considered threatened if it is "likely to become an endangered species within the foreseeable future throughout all or a significant portion of its range." Likely and foreseeable are some of 
Time 1

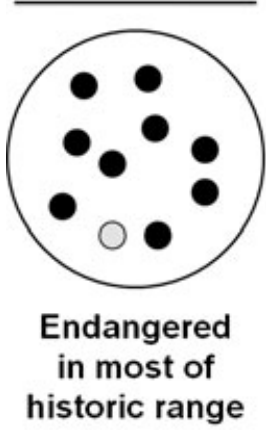

(A)

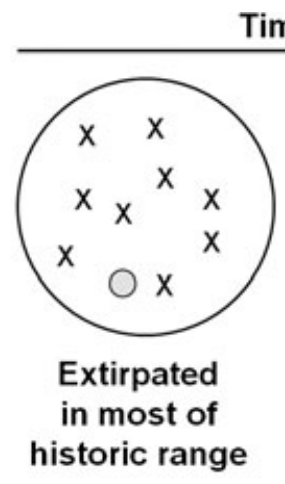

(B)
Time 2

Not at risk in current range
Figure 1. Hypothetical species with 10 historical populations and historical range indicated by large circles, whose status is evaluated at 2 time periods. A (time 1): Nine populations are in danger of extinction (black dots) and one is relatively bealthy (gray dot). B (time 2): Species' status deteriorates as all endangered populations are extirpated (Xs). However, the lone remaining population fills the current range (small circle), so the species might be judged not-at-risk under a framework (C) that restricts SPOIR considerations to only the current range.

the nonscientific words that those involved in ESA determinations have struggled to interpret for years. As with the SPOIR language, these terms are not defined in the ESA, and the responsible agencies have not developed any policy on their interpretation. Even those with experience in ESA implementation can have a wide range of views of how long the foreseeable future is. In one view, foreseeable implies a fairly short time because our uncertainty about future conditions increases rapidly with the length of time under consideration (e.g., one cannot even reliably predict the weather more than a few days ahead). This was the majority view adopted by a group of scientists within the National Oceanic and Atmospheric Administration (NOAA) (Demaster et al. 2004) that reviewed procedures for ESA listing criteria and suggested the following be used as interim guidelines until formal policy interpretations could be developed: likely means $>50 \%$ probability and foreseeable future means 20 years. A contrasting viewpoint is that the foreseeable future could represent a considerable period of time because some long-term processes are predictable (and hence foreseeable) in a general or statistical sense even if specific detailed predictions are not possible.

Regardless of the range of possible viewpoints, each ESA listing determination must, either explicitly or implicitly, have a particular time frame over which it evaluates extinction risk. Let us call this explicit or implicit concept of foreseeable future $y$ years (as in Fig. 1 of Waples et al. 2007a). Our SPOIR framework deals with situations in which the entire species is not currently "likely" to become endangered within $y$ years, but some parts of the range do meet this test. Whatever concept of "foreseeable" is used in the ESA evaluation, our SPOIR framework is concerned with processes that occur on a longer time frame; hence, our framework does provide additional protections that would not be possible if the SPOIR language were omitted. In contrast, D'Elia et al. (2008) seem to have an essentially openended and flexible view of what foreseeable future entails, which misses the distinction we make in our SPOIR framework.

Regarding societal values and SPOIR, it is true that the ESA (Sec. 2[a] [3]) notes that species are of "esthetic, ecological, educational, historical, recreational, and scientific value to the Nation and its people," and any of these factors might be used to try to interpret the SPOIR language. Whether the agencies charged with implementing the ESA choose to do this is more a legal and policy question than a scientific one. Including societal values, either instead of or in addition to biological criteria, could provide more flexibility for managers and policy makers in achieving societal goals. Nevertheless, it is worth noting that formally incorporating normative considerations into SPOIR evaluations would not come without some costs. First, although the societal values cited above might all be good reasons for conserving biodiversity in general, they are not necessarily good reasons for deciding which units to conserve (Waples 1995). Societal values are notoriously fickle on time frames of relevance to the processes that shape biological diversity; furthermore, at any given point in time diverse and potentially conflicting values might be held by different segments of society, so reaching a consensus might not be easy.

Second, the SPOIR language occurs in the section of the ESA that defines threatened and endangered species, so it is natural to consider how the areas that are currently at risk might affect viability of the entire species. Extinction is a biological process; it implies the permanent loss of the genetic blueprint for creating a certain type of organism. Therefore, focusing on areas of a species' range that are considered important to society but are not real biological units can impede meaningful analysis of extinction risk.

Finally, although we agree with D'Elia et al. (2008) that adoption of a SPOIR policy by the agencies could be useful, we are curious about their claim that incorporating societal values into such a policy would make SPOIR evaluations more consistent and transparent. Our experience suggests the opposite would be a more likely outcome. In particular, whether flexibility in making SPOIR determination is a good or bad thing can depend on one's point of view and on who is implementing the flexibility. Creative applications of a flexible policy can sometimes lead to win-win situations, but many recent legal decisions also testify to the potential abuses of flexibility by regulatory agencies. 
In their comment D'Elia et al. (2008) also cite a memorandum regarding interpretation of the SPOIR language written by the Solicitor of the U.S. Department of the Interior (Solicitor's Opinion; Office of the Solicitor 2007). This document, which was released too late for us to comment on in our original paper (Waples et al. 2007a), stipulates that only the current range of a species is relevant for SPOIR considerations. It is easy to show through reductio argumentation that this approach is logically flawed. Consider the hypothetical example illustrated in Fig. 1. At time 1, an ESA 'species' consists of 10 populations, 9 of which are on the verge of extinction/extirpation while the tenth is relatively healthy (Fig. 1A). Most frameworks would probably consider this species to be at risk in a significant portion of its range. After a (perhaps short) period of time, the 9 at-risk populations wink out, leaving a single remnant population (Fig. 1B). Clearly, the status of this species has declined from time 1 to time 2 , because extirpation of $90 \%$ of its historical populations occurred during that interval. Under the shifting-baseline framework articulated in the Solicitor's Opinion, however, the species can now be considered to be not at risk, because the sole remaining population occupies most or all of the current range of the species (Fig. 1C). This process of periodically recalibrating expectations based on current conditions has been identified as a major obstacle to sound conservation and management of biodiversity (Pauly 1995; Dayton et al. 1998). In addition, if this approach were widely adopted it would create incentives that could work against fundamental goals of the ESA. For example, regulators might be inclined to delay listing decisions in the hope that critically endangered populations would disappear, allowing the current range of the species to be recalibrated downwards. Worse, vulnerable populations might become targets for extermination by those wanting to head off possible ESA listings.

In contrast, in our framework a species' historical range is an important reference point for evaluating future viability. A species might be viable even after substantial reductions in abundance and/or distribution, but the historical template provides our best guide to conditions that are conducive to long-term persistence. Therefore, as a species' status increasingly departs from the historical template, the default presumption shifts from "likely to be viable" to "likely not to be viable"; concurrently, the burden of proof shifts from requiring evidence that the species is at risk to requiring evidence that the species is not at risk. In a situation like that depicted in Fig. 1B, where a species is reduced to a small fraction of its historical range, compelling arguments would be required to demonstrate why the species is still viable in its greatly diminished state.

\section{Acknowledgments}

We thank D. Darm and G. Brown for useful discussions. The views expressed herein are those of the authors and do not necessarily represent the views of NOAA Fisheries.

\section{Literature Cited}

Center for Biological Diversity v. U.S. Fish and Wildlife Service. 2007. U.S. Dist. LEXIS 16175 (D. Colo. 8 March 2007).

Dayton, P. K., M. J. Tegner, P. B. Edwards, and K. L. Riser. 1998. Sliding baselines, ghosts, and reduced expectations in kelp forest communities. Ecological Applications 8:309-322.

D'Elia, J., M. Zwartjes, and S. McCarthy. 2008. Considering legal viability and societal values when deciding what to conserve under the U.S. Endangered Species Act. Conservation Biology 23:in press.

Defenders of Wildlife v. Norton. 2001. 258 F.3d 1136 (9th Cir.).

DeMaster, D., R. Angliss, J. Cochrane, P. Mace, R. Merrick, M. Miller, S. Rumsey, B. Taylor, G. Thompson, and R. Waples. 2004. Recommendations to NOAA Fisheries: ESA listing criteria by the Quantitative Working Group, 10 June 2004. Technical memorandum NMFS-F/SPO-67. National Oceanic and Atmospheric Administration, Washington, D.C.

Nelson, M. P., J. A. Vucetich, and M. K. Phillips. 2007. Normativity and the meaning of endangered: response to Waples et al. 2007. Conservation Biology 21:1646-1648.

Office of the Solicitor. 2007. The meaning of "in danger of extinction throughout all or a significant portion of its range." Memorandum M-37013 from the Solicitor to the Director of the U.S. Fish and Wildlife Service (16 March). U.S. Department of the Interior, Office of the Solicitor, Washington, D.C. Available from http://www.doi.gov/solicitor/M37013.pdf (accessed May 2008).

Pauly, D. 1995. Anecdotes and the shifting baseline syndrome of fisheries. Trends in Ecology \& Evolution 10:430.

Vucetich, J. A., M. P. Nelson, and M. K. Phillips. 2006. The normative dimension and legal meaning of endangered and recovery in the U.S. Endangered Species Act. Conservation Biology 20:1383-1390.

Waples, R. S. 1995. Evolutionarily significant units and the conservation of biological diversity under the Endangered Species Act. American Fisheries Society Symposium 17:8-27.

Waples, R. S., P. Adams, J. Bohnsack, and B. L. Taylor. 2007a. A biological framework for evaluating whether an ESA species is threatened or endangered in a "significant portion of its range." Conservation Biology 21:964-974.

Waples, R. S., P. B. Adams, J. Bohnsack, and B. L. Taylor. 2007b. Normativity redux. Conservation Biology 21:1649-1650. 